\title{
Hypertension, Hypertriglyceridemia, and Impaired Endothelium-dependent Vascular Relaxation in Mice Lacking Insulin Receptor Substrate-1
}

\author{
Hideki Abe, ${ }^{\star}$ Nobuhiro Yamada, ${ }^{\ddagger}$ Katsuo Kamata, $\|$ Tomoyuki Kuwaki, ${ }^{\S}$ Masako Shimada, ${ }^{\ddagger}$ Junichi Osuga, ${ }^{\ddagger}$ Futoshi Shionoiri, ${ }^{\ddagger}$ \\ Naoya Yahagi,, Takashi Kadowaki, ${ }^{\ddagger}$ Hiroyuki Tamemoto, ${ }^{\ddagger}$ Shun Ishibashi, ${ }^{\ddagger}$ Yoshio Yazaki, ${ }^{\ddagger}$ and Masatoshi Makuuchi ${ }^{\star}$ \\ *Second Department of Surgery, ${ }^{\ddagger}$ Third Department of Internal Medicine, Faculty of Medicine, University of Tokyo, Tokyo, Japan; \\ ${ }^{\S}$ Second Department of Physiology, School of Medicine, Chiba University, Chiba, Japan; and Department of Physiology and \\ Morphology, Institute of Medicinal Chemistry, Hoshi University, Tokyo, Japan
}

\begin{abstract}
Insulin resistance is often associated with atherosclerotic diseases in subjects with obesity and impaired glucose tolerance. This study examined the effects of insulin resistance on coronary risk factors in IRS-1 deficient mice, a nonobese animal model of insulin resistance. Blood pressure and plasma triglyceride levels were significantly higher in IRS-1 deficient mice than in normal mice. Impaired endotheliumdependent vascular relaxation was also observed in IRS-1 deficient mice. Furthermore, lipoprotein lipase activity was lower than in normal mice, suggesting impaired lipolysis to be involved in the increase in plasma triglyceride levels under insulin-resistant conditions. Thus, insulin resistance plays an important role in the clustering of coronary risk factors which may accelerate the progression of atherosclerosis in subjects with insulin resistance. (J. Clin. Invest. 1998. 101:1784-1788.) Key words: insulin resistance • hypertension • hypertriglyceridemia • insulin receptor substrate-1 • endothelium-dependent vascular relaxation
\end{abstract}

\section{Introduction}

Insulin receptor substrate- 1 (IRS- 1$)^{1}$ is the major substrate of the insulin receptor and insulin-like growth factor (IGF)-1 receptor tyrosine kinase $(1,2)$. Recent studies have established a homozygous mouse model for targeted disruption of the IRS-1 gene $(3,4)$. IRS-1 mutant mice show retarded embryonal and postnatal growth and develop resistance to glucose-lowering effects of insulin, IGF-1, and IGF-2. Although blood glucose levels do not differ significantly between mutant and control mice either before or after oral glucose loading, serum insulin levels are significantly higher in homozygous mutant mice than

Address correspondence to Nobuhiro Yamada, M.D., Third Department of Internal Medicine, University of Tokyo, 7-3-1 Hongo, Bunkyo-ku, Tokyo 113, Japan. Phone: 81-3-3815-5411; FAX: 81-3-56897230.

Received for publication 25 August 1997 and accepted in revised form 12 February 1998.

1. Abbreviations used in this paper: ACh, acetylcholine; HL, hepatic triglyceride lipase; IRS-1, insulin receptor substrate-1; LPL, lipoprotein lipase; SNP, sodium nitroprusside.

J. Clin. Invest.

(C) The American Society for Clinical Investigation, Inc. 0021-9738/98/04/1784/05 \$2.00

Volume 101, Number 8, April 1998, 1784-1788

http://www.jci.org in wild-type or heterozygous mice. Thus, the phenotype of IRS-1 knockout mice resembles non-insulin-dependent diabetes mellitus at the prediabetes stage with insulin resistance.

Insulin resistance with hyperinsulinemia is often associated with clustering of coronary risk factors including hypertension, glucose intolerance, obesity, hypertriglyceridemia, and low plasma HDL-cholesterol levels (5-7). This leads to an increased risk of cardiovascular disease, presumably due to promotion of atherosclerosis. However, the mechanisms associated with this clustering of coronary risk factors in subjects with insulin resistance are not clearly understood. In particular, the specific role of insulin resistance or hyperinsulinemia needs to be clarified. Recently, we developed an animal model of hyperinsulinemia by transplanting a second pancreas into normal rats in order to determine whether increased plasma insulin levels are related to the clustering of coronary risk factors and accelerated progression of atherosclerosis (8). The model shows an endogenous insulin level twice that of normal rats, which influences the process of atherosclerosis by enhancing accumulation of cholesterol esters in the arterial wall. However, this level of insulin shows no relationship to dyslipidemia or hypertension. This study examines whether this clustering syndrome is affected by insulin resistance in nonobese IRS-1 deficient mice.

\section{Methods}

Animals and animal treatment. Female mice homozygous for targeted disruption of the IRS- 1 gene and female wild-type mice that were offspring of heterozygous mice were examined. The genotype of the mice was confirmed by PCR. All mice were fed normal laboratory chow ad libitum. Body weight was measured before examination. Homozygous mice weighed significantly less than wild-type mice as described (Tables I and II) (3), and mesenteric fat mass was not apparently different between IRS-1 deficient and wild-type mice.

Measurement of blood pressure. Blood pressure was measured at the tail artery in 21 homozygous mice and 18 wild-type mice (age, $58 \mathrm{mo}$ ) under restraints using an automatic sphygmomanometer machine (9). Basal blood pressure was measured under restraints in 16 homozygous mice and 18 wild-type mice (age, $58 \mathrm{mo}$ ) using a perfluorocarbon cannula (KZ1101; Kent Scientific Co., CT) inserted into the femoral artery under Nembutal-Na anesthesia (10). After $6 \mathrm{~h}$ of cannulation, pulsatile blood pressure was measured under conscious and unrestrained conditions in a quiet environment after a minimum 30-min acclimatization period between 20:00 and 24:00. Blood pressure was measured every $2.5 \mathrm{~s}$ by a peak detector (AP-611G; NihonKohden, Tokyo, Japan). The data were stored on a tape recorder in addition to heart rate measured using a tachometer (AT-601G; Nihon-Kohden), and then stored in a computer (PC9801RX; NEC, Tokyo, Japan). The mean value of each variable over a 1-h segment composed of 1,440 sample points was calculated.

Vascular reactivity studies. 9 homozygous and 11 wild-type mice (age, $56 \mathrm{mo}$ ) were decapitated, and a section of the thoracic aorta between the aortic arch and diaphragm was removed and placed in oxy- 
Table I. Restrained and Unrestrained Arterial Blood Pressure and Pulse Rate of IRS-1 Deficient and Wild-Type Mice

\begin{tabular}{lcc}
\hline & Homozygous & Wild-Type \\
\hline Restrained study & $(n=21)$ & $(n=18)$ \\
Body weight & $15.6 \pm 2.5^{*}$ & $22.6 \pm 5.6$ \\
Systolic BP & $147 \pm 11^{*}$ & $123 \pm 24$ \\
Unrestrained study & $(n=16)$ & $(n=18)$ \\
Body weight & $18.8 \pm 2.6^{*}$ & $26.1 \pm 4.1$ \\
Systolic BP & $132 \pm 14^{\ddagger}$ & $119 \pm 15$ \\
Diastolic BP & $89 \pm 16^{\ddagger}$ & $79 \pm 12$ \\
Mean BP & $110 \pm 12^{*}$ & $99 \pm 10$ \\
Pulse pressure & $43 \pm 19$ & $40 \pm 20$ \\
Pulse rate & $634 \pm 77$ & $652 \pm 41$ \\
& & \\
\hline
\end{tabular}

Blood pressure was measured at a tail artery in 5-8-mo-old mice in a restrained condition. Furthermore, pulsatile blood pressure was measured under conscious and unrestrained conditions in a quiet environment. Data were expressed as mean \pm SD. $* P<0.01,{ }^{\ddagger} P<0.05$ vs. wild-type.

genated, modified Krebs-Henseleit solution (KHS). KHS consisted of $118.0 \mathrm{mM} \mathrm{NaCl}, 4.7 \mathrm{mM} \mathrm{KCl}, 25.0 \mathrm{mM} \mathrm{NaHCO}{ }_{3}, 1.8 \mathrm{mM} \mathrm{CaCl}_{2}$, $1.2 \mathrm{mM} \mathrm{NaH}_{2} \mathrm{PO}_{4}, 1.2 \mathrm{mM} \mathrm{MgSO}_{4}$, and $11.0 \mathrm{mM}$ dextrose. The aorta was cleaned of loosely adhering fat and connective tissue and cut into rings ( $3 \mathrm{~mm}$ long). The tissue was placed in a well-oxygenated $(95 \%$ $\mathrm{O}_{2} / 5 \% \mathrm{CO}_{2}$ ) bath of $10 \mathrm{ml} \mathrm{KHS}$ at $37^{\circ} \mathrm{C}$ with one end connected to a tissue holder and the other to a force-displacement transducer (TB612T; Nihon-Kohden). The tissue was equilibrated for 60 min under resting tension of $1.0 \mathrm{~g}$, which is optimal for inducing the maximal concentration in all vessels used. KHS in the bath was replaced every $20 \min (11,12)$.

Relaxation response to acetylcholine (ACh; Daiichi Pharmaceutical Co. Ltd., Tokyo, Japan) and sodium nitroprusside (SNP; Sigma Chemical Co., St. Louis, MO) was expressed as a percentage of decreased tension in contractile force induced by $3 \times 10^{-8}$ to $1 \times 10^{-7} \mathrm{M}$ U46619, a derivative of thromboxane $\mathrm{A}_{2}$. For relaxation studies, the aortic rings were precontracted with $3 \times 10^{-8}$ to $1 \times 10^{-7} \mathrm{M} \mathrm{U} 46619$. This concentration produced $85-90 \%$ of the maximal response. Aortic rings, which were weighed at the end of each experiment, were precontracted with $3 \times 10^{-8}$ to $1 \times 10^{-7} \mathrm{M} \mathrm{U} 46619$ to ensure that they could develop a tension of $\sim 100 \mathrm{mg} / \mathrm{mg}$ tissue in both agematched wild-type and homozygous mice. When U46619-induced contraction reached a plateau, ACh $\left(10^{-9}\right.$ to $\left.10^{-5} \mathrm{M}\right)$ and SNP $\left(10^{-9}\right.$ to $10^{-5} \mathrm{M}$ ) were added cumulatively. Each aortic ring was exposed to only one relaxant agent.

Measurement of plasma lipids and fat loading test. The blood of 2-3, 4-5, and 6-12-mo-old homozygous $(n=17)$ and wild-type mice $(n=21)$ was collected after a 6-h fast from 9:00 a.m. to 2:00 p.m. Blood was collected from the retroorbital plexus using heparincoated capillaries and transferred to an ice-cold tube. Plasma concentrations of triglycerides, cholesterol, and FFA were determined enzymatically. HPLC was applied to show elution patterns with two distinguished elution peaks of the two major lipoprotein classes, apo B containing lipoproteins and HDL, which were used to determine HDL-cholesterol levels (13).

After the 6-h fast, postheparin plasma of 6-12-mo-old homozygous $(n=12)$ and wild-type $(n=16)$ mice was sampled 3 min after a bolus injection of heparin $(100 \mathrm{U} / \mathrm{kg})$ into the external jugular vein. Lipoprotein lipase (LPL) activity was assayed by the method described by Nilsson-Ehle and Schotz (14). Postheparin plasma was assayed in the presence or absence of $1 \mathrm{M} \mathrm{NaCl}$ in order to estimate both LPL and hepatic triglyceride lipase (HL) activity. Lipase activity in the presence of $1 \mathrm{M} \mathrm{NaCl}$ represented HL activity. LPL activity was calculated by subtracting HL activity from lipase activity in the absence of $1 \mathrm{M} \mathrm{NaCl}$ (15). LPL activity in adipose tissue derived from the utero-ovarian region was assayed as described (15).

During the 6-h fast, at which time the mice were given ad libitum access to water, olive oil ( $16.7 \mu \mathrm{l} / \mathrm{g}$ body wt) was introduced intragastrically using a cannula to 8-10-mo-old homozygous $(n=4)$ and wildtype $(n=4)$ mice. After fat loading, $\sim 50 \mu \mathrm{l}$ of blood was collected serially at $0,0.5,1,2,3$, and $5 \mathrm{~h}$, and plasma triglyceride levels were measured enzymatically (15).

Statistical analysis. Data were analyzed by the Mann-Whitney U test and expressed as mean \pm SD. $P<0.05$ was considered statistically significant.

\section{Results}

Blood pressure. Under restrained conditions, systolic arterial blood pressure was significantly higher in homozygous mice than in wild-type mice $(147 \pm 11$ vs. $123 \pm 24 \mathrm{mmHg}, P<0.01)$ (Table I), in contrast to unrestrained conditions in which systolic, diastolic, and mean arterial blood pressure were all significantly higher in homozygous mice than in wild-type mice (Table I). Systolic/diastolic pressure was $132 \pm 14 / 89 \pm 16 \mathrm{mmHg}$ in homozygous mice and $119 \pm 15 / 79 \pm 12 \mathrm{mmHg}$ in wild-type mice. Mean blood pressure was $110 \pm 12 \mathrm{mmHg}$ in homozygous mice and $99 \pm 10 \mathrm{mmHg}$ in wild-type mice, $P<0.01$. Pulse

Table II. Plasma Lipid Levels in IRS-1 Deficient and Wild-Type Mice

\begin{tabular}{|c|c|c|c|c|c|c|}
\hline & & Body weight & Triglyceride & Cholesterol & HDL & FFA \\
\hline & & $g$ & $m g / d l$ & $m g / d l$ & $m g / d l$ & $\mu e q / l i t e r$ \\
\hline \multicolumn{7}{|c|}{ Homozygous mice } \\
\hline \multirow[t]{4}{*}{ (months) } & $2-3$ & $15.2 \pm 1.6^{*}$ & $51.2 \pm 23.8^{* *}$ & $75.0 \pm 12.9$ & - & - \\
\hline & $4-5$ & $15.8 \pm 1.3 *$ & $47.9 \pm 19.3 *$ & $76.0 \pm 11.3$ & - & - \\
\hline & $6-12$ & $17.8 \pm 2.3^{*}$ & $53.1 \pm 22.5 *$ & $75.4 \pm 6.4$ & $54.7 \pm 7.6^{\ddagger}$ & $503.7 \pm 122.5$ \\
\hline & & $(n=17)$ & $(n=17)$ & $(n=17)$ & $(n=9)$ & $(n=21)$ \\
\hline \multicolumn{7}{|c|}{ Wild-Type mice } \\
\hline \multirow[t]{4}{*}{ (months) } & $2-3$ & $21.0 \pm 2.0$ & $33.1 \pm 19.8$ & $80.4 \pm 9.0$ & - & - \\
\hline & $4-5$ & $23.8 \pm 1.3$ & $28.4 \pm 8.0$ & $81.9 \pm 11.2$ & - & - \\
\hline & $6-12$ & $24.5 \pm 1.6$ & $33.8 \pm 6.7$ & $79.6 \pm 9.7$ & $68.9 \pm 8.5$ & $529.7 \pm 149.3$ \\
\hline & & $(n=21)$ & $(n=21)$ & & & \\
\hline
\end{tabular}

Data were analyzed by the Mann-Whitney $\mathrm{U}$ test and expressed as mean $\pm \mathrm{SD} .{ }^{*} P<0.01,{ }^{\ddagger} P<0.02$ vs. wild-type. 


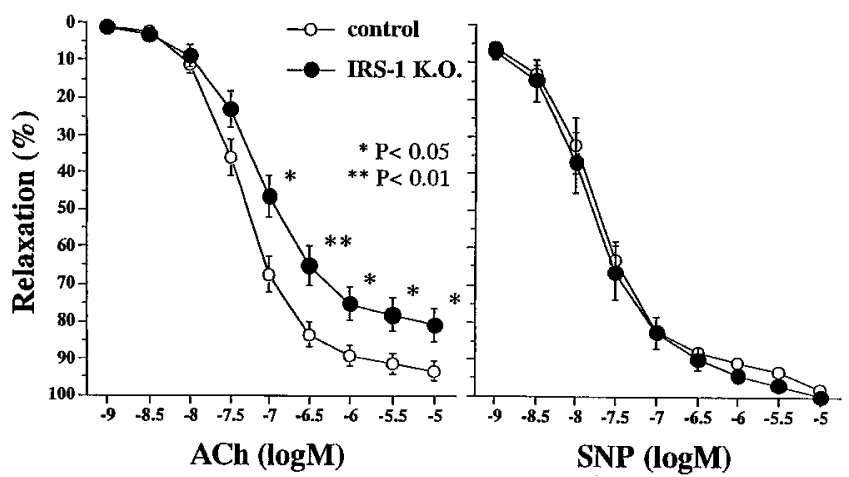

Figure 1. Vascular reactivity in aortic strip. A section of the thoracic aorta between the aortic arch and diaphragm was used. The aortic rings were precontracted with an equieffective concentration of U46619. When the U46619-induced contraction reached a plateau, $\mathrm{ACh}$ and SNP were added cumulatively. The relaxation response to $\mathrm{ACH}(l e f t)$ and SNP (right) was expressed as a percentage of the decreased tension in contractile force induced by $3 \times 10^{-8}$ to $1 \times 10^{-7} \mathrm{M}$ U46619 (mean \pm SD).

pressure and pulse rate did not differ significantly between homozygous and wild-type mice.

Vascular reactivity in aortic rings. The mechanisms underlying elevation in arterial blood pressure were examined in order to elucidate vascular reactivity in aortic rings of IRS-1 deficient mice (Fig. 1). When the U46619 $\left(3 \times 10^{-8}\right.$ to $1 \times 10^{-7}$ $\mathrm{M})$-induced contraction reached a plateau, ACh $\left(10^{-9}\right.$ to $\left.10^{-5} \mathrm{M}\right)$ was added cumulatively. ACh caused concentration-dependent relaxation in aortic strips. This relaxation was significantly reduced in aortic strips from homozygous mice compared with wild-type mice. In contrast, relaxation caused by SNP $\left(10^{-9}\right.$ to $\left.10^{-5} \mathrm{M}\right)$, which is an endothelium-independent agent and activates soluble guanylate cyclase, did not differ significantly between homozygous and wild-type mice.

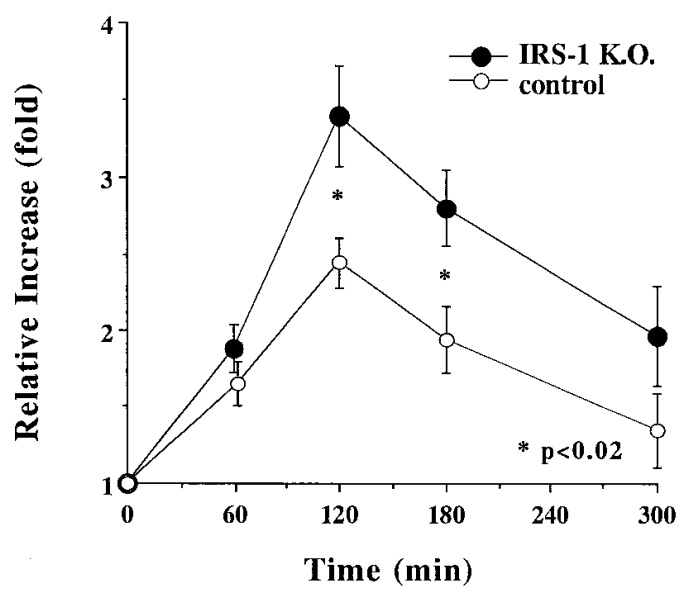

Figure 2. Plasma triglyceride levels after fat loading test. After a 6-h fast, olive oil ( $16.7 \mu \mathrm{l} / \mathrm{g}$ body wt) was loaded intragastrically to homozygous $(n=8)$ and wild-type $(n=8)$ mice. Before and after fat loading, blood was collected serially, and plasma triglyceride levels were measured. The relative increase of plasma triglyceride levels after fat loading compared with that before fat loading was expressed as mean $\pm \mathrm{SE}$.
Table III. LPL Activities in IRS-1 Deficient and Wild-Type Mice

\begin{tabular}{lcc}
\hline & Postheparin plasma & Adipose tissue \\
\hline & $\mu$ mol FFA $/ \mathrm{h} / \mathrm{ml}$ & $\mu \mathrm{mol} F F A / h / g$ \\
Homozygous mice & $24.2 \pm 5.4^{*}$ & $3.3 \pm 1.7^{\ddagger}$ \\
& $(n=16)$ & $(n=7)$ \\
Wild-type mice & $36.0 \pm 13.9$ & $5.7 \pm 2.3$ \\
& $(n=12)$ & $(n=7)$ \\
\hline
\end{tabular}

LPL activities in postheparin plasma and adipose tissue were measured in 6-12-mo-old mice. Data were analyzed by the Mann-Whitney U test and expressed as mean \pm SD. ${ }^{*} P<0.01,{ }^{\ddagger} P<0.05$ vs. wild-type.

Plasma lipid levels. Plasma triglyceride levels after the 6-h fast in homozygous mice were significantly higher than in wildtype mice at each measurement (Table II). This difference was 1.6-fold in 2-3-mo-old mice (homozygous/wild-type: $51.2 \pm 23.8 / 33.1 \pm 19.8 \mathrm{mg} / \mathrm{dl}$ ) and 1.7-fold in 4-5-mo-old mice (homozygous/wild-type: 47.9 $\pm 19.3 / 28.4 \pm 8.0 \mathrm{mg} / \mathrm{dl}$ ). Plasma cholesterol and FFA levels did not differ significantly between the two groups. HPLC analysis of the lipoprotein profiles revealed a significant decrease in plasma HDL-cholesterol levels (homozygous/wild-type: $54.7 \pm 7.6 / 68.9 \pm 8.5 \mathrm{mg} / \mathrm{dl}$, Table II).

Fat loading test. Lipolysis of plasma triglycerides was examined by loading exogenous triglycerides as dietary fat (Fig. 2). The increase in plasma triglyceride level was significantly greater in homozygous mice than in wild-type mice throughout the experimental period. Plasma triglyceride peaked $2 \mathrm{~h}$ after loading in both wild-type and homozygous mice. The peak height in homozygous mice was significantly higher than in wild-type mice $(P<0.02)$.

LPL activity in postheparin plasma after the 6-h fast was significantly lower in homozygous mice than in wild-type mice (Table III), whereas HL activity did not differ significantly between the two groups (data not shown). LPL activity in adipose tissue was also significantly lower in homozygous mice than in wild-type mice (Table III).

\section{Discussion}

Several researchers have suggested recently that insulin resistance contributes to the pathogenesis of atherosclerosis (5-7, 16). In this study, we observed IRS-1 deficiency-induced insulin resistance to lead to increased blood pressure and plasma triglyceride levels, implicating involvement of insulin resistance in both of these coronary risk factors. IRS-1 is the major substrate of the insulin receptor kinase and mediates the signal pathways of insulin and IGF-1 $(1,2)$, therefore the phenotype of IRS-1 deficient mice reflects both defects of insulin and IGF-1 signaling. IRS-1 deficient mice demonstrate growth retardation and resistance to the glucose-lowering effect of insulin $(3,4)$. Recent studies have shown insulin resistance in IRS-1 deficient mice to differ among tissues (17). IRS-1 plays a central role in the signaling pathways of insulin in muscle and adipose tissues. Furthermore, IRS-2 has been demonstrated to compensate for IRS-1 deficiency in the liver of IRS-1 deficient mice. Thus, insulin resistance in IRS- 1 deficient mice appears to be primarily due to resistance in muscle and adipose tissues. 
Epidemiological studies have demonstrated an association between obesity, insulin resistance, and hypertension $(18,19)$. Subsequent studies have suggested that essential hypertension even in lean individuals is related to insulin resistance and hyperinsulinemia $(20,21)$. The mechanism associated with hypertension in insulin resistance with hyperinsulinemia may be related to skeletal muscle blood flow and relative skeletal muscle fiber type (22), vascular endothelial function (23), increased renal sodium reabsorption secondary to hyperinsulinemia (24), increased activity of the sympathetic nervous system (25), or increased cellular cation transport (26). We estimated blood pressure in a nonobese animal model of insulin resistance under restrained and unrestrained conditions. Blood pressure under both conditions was significantly higher in IRS-1 deficient mice than in control mice. Thus, hypertension appears to occur as a result of pathophysiological abnormalities caused by IRS-1 deficiency rather than increased sympathetic activity during the experiment. It is possible that relatively low body weight in IRS-1 deficient mice may influence blood pressure. However, we found high blood pressure in IRS-1 deficient mice as compared with body weight-matched control mice. Furthermore, secondary hyperinsulinemia may have been responsible for hypertension in the present animal model. However, in our previous study, hyperinsulinemia did not affect blood pressure in either normal Wistar or SHR rats with two pancreas, despite a twofold increase in plasma insulin after pancreas transplantation (8). Similar plasma insulin levels were observed in the IRS-1 deficient mice (3) and therefore are not likely to influence blood pressure. Thus, insulin resistance appears to be a cause of hypertension in IRS-1 deficient mice, although high insulin levels caused by insulin resistance may play a role in the elevation of blood pressure.

Endothelium-dependent relaxation of the aorta was reduced in IRS-1 deficient mice, whereas endothelium-independent relaxation did not differ between IRS-1 deficient and control mice. Nitric oxide, a potent vasodilator produced by endothelial cells, has been proposed as the major form of endothelium-dependent relaxing factor which mediates vascular relaxation in response to $\mathrm{ACh}(27,28)$. A recent study reported that mice lacking the gene for endothelial nitric oxide synthase show hypertension (29), suggesting that a resulting impairment in endothelium-dependent vascular relaxation is involved in the pathophysiology of hypertension. Impaired endothelium-dependent vascular relaxation has been observed in genetically diabetic rats (30), streptozotocin-induced diabetic rats (31), and streptozotocin-induced diabetic mice (11). However, the role of insulin resistance in endothelium-dependent vascular relaxation is not yet known. Since glucose tolerance is normal in IRS-1 deficient mice (3), insulin resistance may be responsible for impaired endothelium-dependent relaxation of the aorta.

High plasma triglyceride and low plasma HDL-cholesterol levels, which are inversely correlated, are common clinical findings in the insulin-resistant states which include diabetes mellitus, obesity, and syndrome X (32). Plasma triglyceride levels increased 1.6-fold and plasma HDL-cholesterol levels decreased 0.79 -fold in IRS-1 deficient mice. Two underlying mechanisms may explain the increase in plasma triglycerides associated with insulin resistance in mutant mice: overproduction of VLDL in the liver and decreased clearance of VLDL and chylomicrons $(33,34)$. Impaired insulin action not only stimulates lipolysis, increasing delivery of FFA to the liver and consequently increasing production of triglycerides, but also reduces LPL activity. LPL is an enzyme located on the endothelial surface of adipose tissue and skeletal and heart muscle which hydrolyzes triglycerides in chylomicron and VLDL (35). LPL activity of postheparin plasma and adipose tissue of IRS-1 deficient mice showed a significant reduction in this study, leading to decreased hydrolysis of lipoprotein triglycerides. In accordance with low LPL activity, a significantly greater increment in plasma triglyceride after administration of fat loading was observed in IRS-1 deficient mice as compared with normal mice. Plasma FFA levels are regulated by the transfer of FFA between plasma and adipose tissue $(36,37)$, which involves LPL and hormone-sensitive lipase (38). Lipolysis by hormonesensitive lipase in adipose tissue may be enhanced in the insulin-resistant state of IRS-1 deficient mice (39). However, plasma FFA levels did not increase in IRS-1 deficient mice. Thus, hypertriglyceridemia in IRS-1 deficient mice may be caused by defective hydrolysis of plasma triglycerides rather than an increased delivery of FFA to the liver.

The present results suggest that insulin resistance plays an essential role both in the clustering of coronary risk factors such as hypertension and hypertriglyceridemia and in reduced endothelium-dependent vascular relaxation. Endothelial dysfunction such as impaired endothelium-dependent vascular relaxation are considered to be closely related to the pathogenesis of atherosclerosis (28). Therefore, not only clustering of coronary risk factors but also impaired endothelium-dependent vascular relaxation may be involved in the progression of atherosclerosis observed in insulin resistance.

\section{References}

1. Sun, X.J., P. Rothenberg, C.R. Kahn, J.M. Backer, E. Araki, P.A. Wilden, D.A. Cahill, B.J. Goldstein, and M.F. White. 1991. Structure of the insulin receptor substrate IRS-1 defines a unique signal transduction protein. $\mathrm{Na}$ ture. 352:73-77.

2. Kadowaki, T., S. Koyasu, E. Nishida, K. Tobe, T. Izumi, F. Takaku, H. Sakai, I. Yahara, and M. Kasuga. 1987. Tyrosine phosphorylation of common and specific sets of cellular proteins rapidly induced by insulin, insulin-like growth factor I, and epidermal growth factor in an intact cell. J. Biol. Chem. 262:7342-7350.

3. Tamemoto, H., T. Kadowaki, K. Tobe, T. Yagi, H. Sakura, T. Hayakawa, Y. Terauchi, K. Ueki, Y. Kaburagi, S. Satoh, et al. 1994. Insulin resistance and growth retardation in mice lacking insulin receptor substrate-1. Nature. 372: $182-186$.

4. Araki, E., M.A. Lipes, M.E. Patti, J.C. Bruning, B. Haag III, R.S. Johnson, and C.R. Kahn. 1994. Alternative pathway of insulin signaling in mice with targeted disruption of the IRS-1 gene. Nature. 372:186-190.

5. Kaplan, N.M. 1989. The deadly quartet. Arch. Intern. Med. 149:15141520.

6. Reaven, G.M. 1988. Banting lecture 1988. Role of insulin resistance in human disease. Diabetes. 37:1595-1607.

7. Zavaroni, I., E. Bonora, M. Pagliara, E. Dall'Aglio, L. Luchetti, G. Buonanno, P.A. Bonati, M. Bergonzani, L. Gnudi, M. Passeri, and G. Reaven. 1989. Risk factors for coronary artery disease in healthy persons with hyperinsulinemia and normal glucose tolerance. N. Engl. J. Med. 320:702-706.

8. Abe, H., Y. Bandai, M. Makuuchi, Y. Idezuki, M. Nozawa, T. Oka, J. Ohsuga, Y. Watanabe, T. Inaba, and N. Yamada. 1996. Hyperinsulinemia accelerates accumulation of cholesterol ester in aorta of rats with transplanted pancreas. Diabetologia. 39:1276-1283.

9. Yamakoshi, K., H. Shimazu, and T. Togawa. 1979. Indirect measurement of instantaneous arterial blood pressure in the rat. Am. J. Physiol. 237:H632H637.

10. Kurihara, Y., H. Kurihara, H. Suzuki, T. Kodama, K. Maemura, H. Nagai, T. Kuwaki, W.H. Cao, N. Kamada, K. Jishage, et al. 1994. Elevated blood pressure and craniofacial abnormalities in mice deficient in endothelin-1. $\mathrm{Na}$ ture. 368:703-710.

11. Kamata, K., M. Sugiura, S. Kojima, and Y. Kasuya. 1996. Preservation of endothelium-dependent relaxation in cholesterol-fed and streptozotocininduced diabetic mice by the chronic administration of cholestyramine. $\mathrm{Br} . \mathrm{J}$. Pharmacol. 118:385-391. 
12. Miyata, N., K. Tsuchida, S. Okuyama, S. Otomo, K. Kamata, and T. Kasuya. 1992. Age-related changes in endothelium-dependent relaxation in aorta from genetically diabetic WBN/Kob rats. Am. J. Physiol. 262:H1104-H1109.

13. Shimano, H., N. Yamada, N. Katsuki, M. Shimada, T. Gotoda, K. Harada, T. Murase, C. Fukazawa, F. Takaku, and Y. Yazaki. 1992. Overexpression of apolipoprotein $\mathrm{E}$ in transgenic mice: a marked reduction in plasma lipoproteins except high density lipoprotein. Proc. Natl. Acad. Sci. USA. 89:17501754.

14. Nilsson-Ehle, P., and M.C. Schotz. 1976. A stable, radioactive substrate emulsion for assay of lipoprotein lipase. J. Lipid Res. 17:536-541.

15. Shimada, M., H. Shimano, T. Gotoda, K. Yamamoto, M. Kawamura, T. Inaba, Y. Yazaki, and N. Yamada. 1993. Overexpression of human lipoprotein lipase in transgenic mice. J. Biol. Chem. 268:17924-17929.

16. Williams, B. 1994. Insulin resistance: the shape of things to come. Lancet. 344:521-524.

17. Yamauchi, T., K. Tobe, H. Tamemoto, K. Ueki, T. Kaburagi, R. Yamamoto-Honda, Y. Takahashi, F. Yoshizawa, S. Aizawa, Y. Akanuma, et al. 1996. Insulin signaling and insulin actions in the muscles and livers of insulin-resistant, insulin receptor substrate 1-deficient mice. Mol. Cell. Biol. 16:3074-3084.

18. Modan, M., H. Halkin, S. Almog, A. Lusky, A. Eshkil, M. Shefi, A. Shitrit, and Z. Fuchs. 1985. Hyperinsulinemia: a link between hypertension, obesity and glucose intolerance. J. Clin. Invest. 75:809-817.

19. Lucas, C.P., J.A. Estigarribia, L.L. Darga, and G.M. Reaven. 1985. Insulin and blood pressure in obesity. Hypertension. 7:702-706.

20. Ferrannini, E., G. Buzzigoli, R. Bonadonna, M.A. Giorico, M. Oleggini, L. Graziadei, R. Pedrinelli, L. Brandi, and S. Bevilacqua. 1987. Insulin resistance in essential hypertension. N. Engl. J. Med. 15:350-357.

21. Bonora, E., I. Zavaroni, O. Alpi, A. Pezzarossa, F. Bruschi, E. Dall'Aglio, L. Guerra, C. Coscelli, and U. Butturini. 1987. Relationship between blood pressure and plasma in insulin in non-obese and obese non-diabetic subjects. Diabetologia. 30:719-723.

22. Lillioja, S., A.A. Young, and C.L. Culter. 1987. Skeletal muscle capillary density and fiber type are possible determinants of in vivo insulin resistance in man. J. Clin. Invest. 80:415-424.

23. Steinberg, H.O., G. Brechtel, A. Johnson, N. Fineberg, and A.D. Baron. 1994. Insulin mediated skeletal muscle vasodilation is nitric oxide dependent. A novel action of insulin to increase nitric oxide release. J. Clin. Invest. 94:11721179.

24. DeFronzo, R.A. 1981. The effect of insulin on renal sodium metabolism: a review with clinical implications. Diabetologia. 21:165-171.

25. Rowe, J.W., J.B. Young, K.L. Minaker, A.L. Stevens, J. Pallotta, and L.
Landsberg. 1981. Effect of insulin and glucose infusions on sympathetic nervous system activity in normal man. Diabetes. 30:219-225.

26. Moore, R.D. 1983. Effects of insulin upon ion transport. Biochim. Biophys. Acta. 737:1-49.

27. Palmer, R.M.J., A.G. Ferrige, and S. Moncada. 1987. Nitric oxide release accounts for the biological activity of endothelium-derived relaxing factor. Nature. 327:524-526.

28. Moncada, S., R.M.J. Palmer, and E.A. Higgs. 1991. Nitric oxide: physiology, pathology, and pharmacology. Pharmacol. Rev. 43:109-142.

29. Huang, P.L., Z. Huang, H. Mashimo, K.D. Bloch, M.A. Moskowitz, J.A. Bevan, and M.C. Fishman. 1995. Hypertension in mice lacking the gene for endothelial nitric oxide synthase. Nature. 377:239-242.

30. Meraji, S., L. Jayakody, P.J. Senaratne, A.B.R. Thomson, and T. Kappagoda. 1987. Endothelium-dependent relaxation in aorta of BB rat. Diabetes. 36: 978-981.

31. Kamata, K., N. Miyata, and Y. Kasuya. 1989. Impairment of endothelium-dependent relaxation and changes in levels of cyclic GMP in aorta from streptozotocin-induced diabetic rats. Br. J. Pharmacol. 97:614-618.

32. Howard, B.V. 1987. Lipoprotein metabolism in diabetes mellitus. $J$. Lipid Res. 28:613-628.

33. Reaven, E.P. and G.M. Reaven. 1974. Mechanisms for development of diabetic hypertriglyceridemia in streptozotocin-treated rat. Effect of diet and duration of insulin deficiency. J. Clin. Invest. 54:1167-1178.

34. Shimada, M., S. Ishibashi, T. Gotoda, M. Kawamura, K. Yamamoto, T. Inaba, K. Harada, J. Ohsuga, S. Perrey, Y. Yazaki, and N. Yamada. 1995. Overexpression of human lipoprotein lipase protects diabetic transgenic mice from diabetic hypertriglyceridemia and hypercholesterolemia. Arterioscler. Thromb. Vasc. Biol. 15:1688-1694.

35. Eckel, R.H. 1989. Lipoprotein lipase: a multifunctional enzyme relevant to common metabolic diseases. N. Engl. J. Med. 320:1060-1068

36. Ruderman, N.B., C.J. Toews, and E. Shafrir. 1969. Role of free fatty acids in glucose homeostasis. Arch. Intern. Med. 123:299-313.

37. Pelkonen, R., T.A. Miettinen, M.R. Taskinen, and E.A. Nikkila. 1968 Effect of acute elevation of plasma glycerol, triglyceride and FFA levels on glucose utilization and plasma insulin. Diabetes. 17:76-82.

38. Coppack, S.W., R.D. Evans, R.M. Fisher, K.N. Frayn, G.F. Gibbons, S.M. Humphreys, M.L. Kirk, J.L. Potts, and T.D.R. Hockaday. 1992. Adipose tissue metabolism in obesity: lipase action in vivo before and after a mixed meal. Metabolism. 41:264-272.

39. Lafontan, M., and M. Berlan. 1993. Fat cell adrenergic receptors and the control of white and brown fat cell function. J. Lipid Res. 34:1057-1091. 